\title{
Enhancing acetate selectivity by coupling anodic oxidation in carbon monoxide electroreduction
}

\section{Sean Overa}

University of Delaware

Bradie Crandall

University of Delaware

Bharat Shrimant

Rensselaer Polytechnic Institute

Ding Tian

Rensselaer Polytechnic Institute

Byung Hee Ko

University of Delaware https://orcid.org/0000-0002-0934-5182

Haeun Shin

university of delaware

Chulsung Bae

Rensselaer Polytechnic Institute

Feng Jiao ( $\boldsymbol{}_{\text {jiao@udel.edu })}$

University of Delaware https://orcid.org/0000-0002-3335-3203

\section{Article}

Keywords:

Posted Date: March 3rd, 2022

DOI: https://doi.org/10.21203/rs.3.rs-1370805/v1

License: (c) (i) This work is licensed under a Creative Commons Attribution 4.0 International License.

Read Full License 


\section{Abstract}

Electrocatalytic conversion of carbon monoxide (CO) is being actively developed as a key component for tandem $\mathrm{CO}_{2}$ electrolysis. Significant effort has been devoted to engineering $\mathrm{CO}$ reduction electrocatalysts for better multi-carbon product selectivity. However, less attention has been paid to other performance parameters, such as liquid product concentration and purity, which are crucial for commercializing CO electrolysis. Here, we present an "internally coupled purification" strategy to substantially improve the acetate concentration and purity in $\mathrm{CO}$ electrolysis. This improvement was achieved by incorporating both an anode electrocatalyst with high ethanol partial oxidation activity as well as an anion-exchange membrane with high ethanol permeability and good alkaline stability. We have successfully demonstrated stable 120-hour continuous operation of the $\mathrm{CO}$ electrolyzer at a fixed current density of $200 \mathrm{~mA} \mathrm{~cm}^{-2}$ and a full cell potential of $<2.3 \mathrm{~V}$, producing an acetate product stream with a concentration of $1.9 \mathrm{M}$ and a purity of $97.7 \%$. By tuning the reaction conditions, we also showed that the concentration of the acetate production stream can be further increased to $7.6 \mathrm{M}$ while maintaining a purity of $>99 \%$. Additional mechanistic investigation revealed the roles of anode electrocatalysts and anion-exchange membranes in enhancing the acetate selectivity in $\mathrm{CO}$ electrolyzers. Finally, a technoeconomic analysis shows that a highly concentrated liquid product stream is essential to reduce the energy consumption associated with the product separation.

\section{Introduction}

As the consequences of rapid climate change continue to intensify, carbon capture and utilization is becoming a critical strategy to mitigate the rising carbon dioxide $\left(\mathrm{CO}_{2}\right)$ levels in the atmosphere. ${ }^{1,2}$ Among all $\mathrm{CO}_{2}$ utilization technologies, electrochemical $\mathrm{CO}_{2}$ reduction $\left(\mathrm{eCO}_{2} \mathrm{R}\right)$ uses $\mathrm{CO}_{2}$ as the carbon feedstock and produces various value-added chemicals. ${ }^{3}$ However, direct $\mathrm{eCO}_{2} \mathrm{R}$ suffers from several technical challenges, such as the formation of unwanted carbonates in alkaline conditions, ${ }^{4}$ low energetic efficiency, and low single-pass $\mathrm{CO}_{2}$ conversion to desired products. ${ }^{4-6}$ Progress has been made to circumvent these issues in direct $\mathrm{eCO}_{2} \mathrm{R}$ using novel materials and reactor designs. ${ }^{7-9}$ One promising strategy is cascade electrolysis (also called two-step tandem electrolysis). In this process, $\mathrm{CO}_{2}$ is first converted electrochemically to $\mathrm{CO}$, followed by further conversion of $\mathrm{CO}$ via electrochemical carbon monoxide (CO) reduction (eCOR). ${ }^{10,11}$ As demonstrated in the literature, eCOR has exhibited a unique capability of achieving a high conversion towards desired multicarbon $\left(\mathrm{C}_{2+}\right)$ products at relatively low cell voltages. ${ }^{12}$ Also, unlike $\mathrm{CO}_{2}$, $\mathrm{CO}$ does not spontaneously react with hydroxide, allowing eCOR to be readily conducted in an alkaline environment without any carbonate formation. The alkaline environment also enables the use of non-precious-metal catalysts to promote the oxygen evolution reaction (OER) at the anode. When electrolysis is conducted in non-alkaline conditions, a precious-metal OER catalyst (e.g., $\left(\mathrm{rO}_{\mathrm{x}}\right)$ is needed for stability. 
Ethylene, ethanol, n-propanol, and acetate are the four major $\mathrm{C}_{2+}$ products observed in Cu-catalyzed eCOR. Due to their large market size and high market value, ${ }^{13}$ there is considerable interest in developing eCOR catalysts and reactor systems that are $\mathrm{C}_{2+}$ product selective and energetically efficient. For example, two-dimensional $\mathrm{Cu}$ nanosheets with the exposed $\mathrm{Cu}(111)$ surface showed an acetate Faradaic efficiency (FE) as high as $48 \% .{ }^{14}$ As well as nanosheets, oxide derived $\mathrm{Cu}$ has been demonstrated to significantly enhance alcohol selectivity to over $40 \% \mathrm{FE} .{ }^{15,16}$ Despite this progress, the majority of the studies in the literature do not produce the desired products in high concentrations or purities and often suffer from a low CO conversion. ${ }^{14,17}$ Recently, Wang and his co-workers reported a porous solid-stateelectrolyte $\mathrm{CO}$ electrolyzer configuration, producing high-purity acetic acid. However, this design required a large full cell potential of $4.06 \mathrm{~V}$ (iR-corrected value) to achieve a current density of $420 \mathrm{~mA} \mathrm{~cm}^{-2}$, partially due to the high cell resistance that results from multiple membranes. This system was also unable to produce acetic acid in concentrations greater than $0.33 \mathrm{M} \cdot{ }^{17,18} \mathrm{~A}$ concentrated product stream (especially for liquid products) is highly desirable to minimize the costs associated with product separation and electrolyte recovery, but high concentrations of liquid products are rarely seen from conventional CO electrolyzers. ${ }^{19,20}$

Membrane electrode assemblies (MEA) are being actively explored for practical $\mathrm{CO}_{2} / \mathrm{CO}$ electrolyzer systems. In principle, they allow for a simplified reactor design and a lower operating cell voltage; thus, allowing for a higher energetic efficiency to be achieved. This has been seen in polymer membrane-based fuel cells and water electrolyzers. ${ }^{11,12,21-23}$ Most MEA studies in eCOR (and $\mathrm{eCO}_{2} \mathrm{R}$ ) focused on engineering cathode catalysts, tuning catalyst-membrane interfaces, and improving cell designs. Much less effort has been devoted to investigating impacts of ion transport across the membrane and anode electrocatalysts on the overall performance of $\mathrm{CO}$ electrolyzers. Here, we report a $\mathrm{CO}$ electrolyzer design based on a Cu cathode catalyst, a nickel-iron anode catalyst, and an anion exchange membrane (AEM), which can produce ethylene and concentrated high-purity acetate at partial current densities up to 506 $\mathrm{mA} \mathrm{cm}{ }^{-2}$ with a full cell energetic efficiency of $44 \%$ towards eCOR products. Distinct from conventional AEM-based designs, the new "internally coupled purification" strategy pairs eCOR on cathode with ethanol partial oxidation at the anode in a single MEA-based electrolyzer. In this system, ethanol is internally converted into acetate, resulting in a highly concentrated acetate product steam (up to $7.6 \mathrm{M}$ ) with a purity of $>97 \%$.

\section{Electrolyzer Design And Performance}

Figure $1 \mathrm{a}$ is a schematic diagram illustrating the key features of the new AEM-based MEA CO electrolyzer design. In conventional three-compartment microfluidic cells, the liquid products (e.g., ethanol, n-propanol, and acetate) are often collected from the cathode chamber. In contrast, the new electrolyzer is designed to produce a concentrated liquid product stream in the anode chamber, which is enabled by an AEM with high permeability for alcohols and acetate. The highly permeable membrane facilitates the diffusion of the liquid products generated at the cathode across the membrane while simultaneously suppressing 
product salt accumulation at the cathode. The gaseous products (mainly ethylene) will remain in the cathode chamber. The final product concentration can also be tuned by adjusting the flow rate of the anolyte or the number of recirculations of the anolyte through the anode chamber. Another essential feature is the choice of an anode catalyst that promotes OER from water and converts alcohols to carboxylates through partial alcohol oxidation reactions (AORs). As the liquid products cross the membrane, the unwanted alcohols (i.e., ethanol and n-propanol) may be further converted into carboxylates (i.e., acetate and n-propionate) at the anode when a suitable anode catalyst is used. The internal-tandem process could serve as a unique strategy to both boost acetate concentration and purity simultaneously in eCOR.

The proof-of-concept demonstration was conducted using an advanced anion exchange membrane (Orion Polymer AMX), a reinforced gas diffusion layer Cu nanoparticle cathode (40-60 nm, Sigma Aldrich), and an electrodeposited $\mathrm{Ni}$-Fe mixed oxide ( $\mathrm{NiFeO}_{x} / \mathrm{Ni}$ foam) anode. A $3 \mathrm{M} \mathrm{KOH}$ solution was used as the anolyte and was circulated through the anode for 24 hours before being refreshed to allow for high acetate concentration. Varying concentrations of $\mathrm{KOH}$ as well as different types of membranes and electrodes were investigated and are discussed in Supplementary Discussion 1. As a critical component of an MEA system, the AMX membrane was chosen due to its high alcohol permeability, good stability in resisting harsh organics, and strong durability in concentrated alkaline conditions. ${ }^{24}$

The as designed cell was shown to be capable of operating continuously for 120 hours at a current density of $200 \mathrm{~mA} \mathrm{~cm}^{-2}$. After the initial 12 hours of operation, the system demonstrated no clear shifts in either cell potential or product FEs. A stable cell potential between 2.15 and $2.23 \mathrm{~V}$ (no iR-correction) was maintained for the duration of the experiment (Fig. 1b). This remarkably steady voltage profile was accompanied by stable FEs towards acetate, hydrogen, and ethylene which were maintained with less than $5 \%$ loss of their initial value following the first 12 hours. During the experiment, gaseous products were monitored every 4 hours via in-line gas chromatography (GC). Acetate concentration and Faradaic efficiency were measured every 24 hours using quantitative ${ }^{1} \mathrm{H}$-nuclear magnetic resonance $\left({ }^{1} \mathrm{H} N \mathrm{NR}\right)$ technique. A maximum acetate concentration of $1.93 \mathrm{M}$ was achieved in this experiment with a molar purity of $96 \%$ and a carbon selectivity of $70-75 \%$ (Figure S1) over other eCOR products (Fig. 1C).

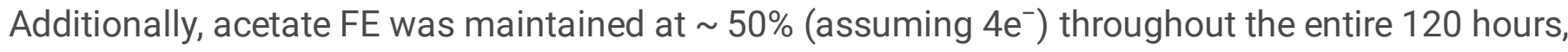
suggesting superior cathode durability (Supplementary Discussion 2 ).

Over the 120-hour experiment, the full cell potential increased minimally from $2.15 \mathrm{~V}$ to $2.23 \mathrm{~V}$ at a rate of $0.7 \mathrm{mV}$ hour $^{-1}$. The X-ray photoelectron spectroscopy (XPS) analysis of the post-reaction cell components (Figure S2) confirmed that there was 23\% loss of Fe from the $\mathrm{NiFeO}_{\mathrm{x}}$ anode. Analysis of the post-reaction cathode (Figure S3) shows no sign of Ni or Fe deposition, suggesting that the cathode was not impacted by the leached $\mathrm{Fe} / \mathrm{Ni}$ from the anode. The single-pass conversion of $\mathrm{CO}$ was maintained at approximately $40 \%$ during the 100 -hour experiment period (Figure S4). At optimal 
operating conditions, the $\mathrm{CO}$ single-pass conversion reached $78 \%$ without suffering from any significant decreases in eCOR performance (Figure S5).

To enhance the acetate concentration in the product stream, we studied the CO electrolyzer performance under a wide range of conditions. During the acetate production process (i.e., CO electrolysis), the pH of the anolyte changed substantially as acetate became more concentrated. Additionally, the cell potential did not change in any significant way until an acetate-to-KOH ratio of 1.2:1 was achieved (Figure S6). By increasing the starting $\mathrm{KOH}$ concentration from 3 to $7 \mathrm{M}$, a remarkable $7.6 \mathrm{M}$ acetate concentration was achieved at a purity of $99.3 \%$ (Fig. 1d). The result represents the highest acetate concentration that has ever been achieved at high purity (>99\%) with an impressive carbon selectivity of $82.4 \%$ (Figure S7). Further increasing the $\mathrm{KOH}$ concentration to $9 \mathrm{M}$ resulted in severe hydrogen evolution, suggesting that a more stable interface is needed to handle such a harsh condition. ${ }^{25}$

\section{Anode Performance For Alcohol Oxidation And Its Impact On Ecor}

Another important observation is the absence of ethanol and n-propanol in the liquid product stream, which resulted in a remarkably high purity of acetate. As both ethanol and n-propanol are usually produced on Cu catalysts in eCOR in appreciable quantities, we speculate that the alcohols produced from the cathode may cross over the membrane to the anode side where they are partially oxidized to the corresponding carboxylates. This may explain why we observed a high purity of acetate (from ethanol partial oxidation) together with a small amount of propionate (from propanol partial oxidation). To verify this, we designed a series of experiments to investigate the potential alcohol partial oxidation in the CO electrolyzer. As ethanol has a low concentration in water during $\mathrm{eCOR}^{26}$ the ideal anode catalyst candidate should be highly selective at ethanol partial oxidation but also excellent at OER as it is still the dominant anodic reaction at high current densities. Therefore, we selected nickel-iron oxide electrodeposited on nickel foam $\left(\mathrm{NiFeO}_{\mathrm{x}} / \mathrm{Ni}\right.$ foam), cobalt oxide electrodeposited on $\mathrm{Ni}$ foam $\left(\mathrm{CoO}_{\mathrm{x}} / \mathrm{Ni}\right.$ foam), bare $\mathrm{Ni}$ foam, and iridium oxide calcinated onto titanium felt $\left(\mathrm{IrO}_{\mathrm{x}} / \mathrm{Ti}\right.$ felt) for this study. The catalyst fabrications were conducted using a previously reported electrodeposition method. ${ }^{27}$ The composition of the electrodeposited anodes were confirmed by X-ray photoelectron spectroscopy (XPS) (Figures S8 and S9) and scanning electron microscopy energy dispersive X-ray analysis (Figure S10).

Initial experiments were carried out in an $\mathrm{H}$-cell to determine the relative activity of the different anodes. By sweeping from 0.7 to $1.75 \mathrm{~V}$ vs RHE at $25 \mathrm{mV} \mathrm{s}^{-1}$, in $1 \mathrm{M} \mathrm{KOH}, \mathrm{NiFeO}_{\mathrm{x}}, \mathrm{CoO}_{\mathrm{x}}$, and IrO $\mathrm{x}$ all achieved a current density $>0.9 \mathrm{~A} \mathrm{~cm}^{-2}$ at $430 \mathrm{mV}$ overpotential (compared to $1.23 \mathrm{~V}$ vs RHE for OER). At the same time, the bare Ni foam had a significantly lower maximum current (Figure 2a). To scan for the activity for alcohol oxidation, $1 \mathrm{M}$ ethanol was introduced as a model alcohol typically produced from eCOR. When 1 $\mathrm{M}$ ethanol was introduced, only $\mathrm{NiFeO}_{\mathrm{x}}$ maintained a significant increase in performance across the entire screened potential range, achieving a total current density of $1.46 \mathrm{~A} \mathrm{~cm}^{-2}$, an increase of $260 \mathrm{~mA} \mathrm{~cm}{ }^{-2}$ compared to just $\mathrm{KOH}$ (Figure 2a). Bare $\mathrm{Ni}$ foam and $\mathrm{CoO}_{x}$ showed an initial increase in performance, but after a brief plateau, they had a sharp decrease in activity at higher overpotential relative to OER (Figure 
2a). $\mathrm{IrO}_{\mathrm{x}}$, under the presence of $1 \mathrm{M}$ ethanol, showed no activity towards ethanol oxidation and suffered in performance (Figure 2a). Interestingly, the presence of ethanol at a concentration as low as $0.01 \mathrm{M}$ has a noticeable impact on $\mathrm{NiFeO}_{\mathrm{x}}$ voltage profiles, suggesting that $\mathrm{NiFeO}_{\mathrm{x}}$ is highly sensitive to alcohols even at a low concentration (Figure S11).

The behavior of the anode catalysts was further investigated in MEA-based flow cells (Figure S12). Anodes were initially tested at a fixed current density ranged from 50 to $600 \mathrm{~mA} \mathrm{~cm}^{-2}$ for OER (Figure $2 \mathrm{~b}$ ). In the alcohol oxidation reaction (AOR) study, a mixture of $2 \mathrm{M} \mathrm{KOH}, 0.5 \mathrm{M}$ ethanol and $0.5 \mathrm{M}$ n-propanol was fed to the reactor, as this is a closer representation of what is produced under Cu-catalyzed eCOR conditions. ${ }^{14,16}$ It was found that the improved activity for $\mathrm{NiFeO}_{x}$ in the presence of alcohols was correlated with a near $100 \%$ selectivity for the conversion of alcohols to carboxylates (Figure S13 and S14). Additionally, $\mathrm{NiFeO}_{x}$ maintained this high selectivity and activity up to an applied $600 \mathrm{~mA} \mathrm{~cm}{ }^{-2}$, achieving an AOR partial current density of $598 \mathrm{~mA} \mathrm{~cm}^{-2}$ (Figure $2 \mathrm{~b}$ and 2c). This high activity for AOR and low overpotential suggest that $\mathrm{NiFeO}_{x}$ is an ideal anode for the internal tandem purification technique.

Based on the initial screening, we further investigated these four anode catalysts in a MEA-based CO electrolyzer to confirm if a significantly higher proportion of carboxylates will be produced when $\mathrm{NiFeO}_{\mathrm{x}}$ is used as the anode compared to $\mathrm{CoO}_{x}$, bare $\mathrm{Ni}$, and $\mathrm{IrO}_{\mathrm{x}}$. When placed in the flow cell, all configurations were shown to be capable of reaching a total current density of $600 \mathrm{~mA} \mathrm{~cm}^{-2}$ in the MEA with a partial current density towards $\mathrm{C}_{2+}$ products of $>500 \mathrm{~mA} \mathrm{~cm}^{-2}$ (Figure $2 \mathrm{~d}$ ), representing $>80 \%$ FE towards $\mathrm{C}_{2+}$ products. As expected, the product spectra varied significantly based on which anode was used in the experiment (Figure S16). Assuming $4 \mathrm{e}^{-}$per acetate, the system achieved an acetate partial current density of $174 \mathrm{~mA} \mathrm{~cm}^{-2}$ and $\mathrm{FE}$ of $29 \%$ (Figure 2e) when using $\mathrm{NiFeO}_{\mathrm{x}}$, significantly more than any other anode. It should be noted that the reported current density does not accurately reflect the eCOR reaction rate, because a fraction of acetate is produced via ethanol partial oxidation reaction (EOR).

To estimate the actual amount of acetate produced via EOR, a control experiment was performed using $\mathrm{IrO}_{\mathrm{x}}$ as the anode as this was the only catalyst which displayed no activity for EOR at high current densities. It was predicted that approximately 7 to $15 \% \mathrm{FE}$ towards acetate was produced via ethanol partial oxidation in this reactor configuration. Acetate partial current density was therefore corrected to account for the EOR contributions (Supplementary Discussion 2), and it was found that the corrected peak acetate current density via eCOR was $260 \mathrm{~mA} \mathrm{~cm}{ }^{-2}$, representing an FE of $43.3 \%$ at $600 \mathrm{~mA} \mathrm{~cm} \mathrm{~cm}^{-2}$ (Figure $2 \mathrm{~d}$ ). This production rate is not only a remarkably high partial current density to produce acetate, but it was also achieved at a total cell voltage of just $2.25 \mathrm{~V}$ (corresponding to a full-cell energetic efficiency of $\sim 44 \%$ ). Additionally, there is nearly a 5 -times increase in carboxylate production relative to alcohols when using $\mathrm{NiFeO}_{\mathrm{x}}$ as the anode (Figure 2e). 
As a result, the amount of $\mathrm{CO}$ going to the desired products, i.e., the carbon selectivity, is boosted significantly by controlling the selectivity at the anode. This allows for a much higher purity of acetate to be produced with a commercial Cu-based cathode (Figure S18). Also, shifting reactor production to $>80 \%$ single target products, as shown by acetate and ethylene accounting for $86 \%$ of all products by anode modification, will result in over $30 \%$ reduction in production costs for $\mathrm{eCO}_{2} \mathrm{R} / \mathrm{eCOR}$ products. ${ }^{19}$ More importantly, the high selectivity and purity of acetate were achieved at a full cell energetic efficiency of $44 \%$ (without any corrections) towards $\mathrm{C}_{2+}$ products at $600 \mathrm{~mA} \mathrm{~cm}^{-2}$ with a two-product energetic efficiency of $37 \%$. This work also showed, for the first time, propionate can be produced in $\mathrm{CO}$ electrolysis at a meaningful rate with a maximum $\mathrm{FE}$ of $11 \%$.

\section{Membrane Influence On Ecor Performance}

To enable the "internally coupled purification" strategy, the anion exchange membrane (AEM) is also a critical component in the high-performance $\mathrm{CO}$ electrolyzer. We investigated 3 AEMs (FAA-3-50, FAAM-40, and MTPN1-TMA) with varying degrees of alcohol permeation rates (Figure S15). The synthesis of mTPN1-TMA is discussed in Supplementary Discussion 3. FAA-3-50 exhibited the highest alcohol crossover through the membrane, whereas FAAM-40 showed nearly no alcohol crossover (Fig. 3a). The AEMs were further evaluated in a MEA-type $\mathrm{CO}$ electrolyzer together with either $\mathrm{NiFeO}_{x}$ or $\operatorname{IrO}_{x}$ as the anode catalyst. The results (Figure S16, 18, \& 19) confirm that the most diffusive membrane, FAA-3-50, enabled the highest carboxylate production rate, achieving a maximum partial current density towards carboxylates of $293.5 \mathrm{~mA} \mathrm{~cm}^{-2}$ at an $\mathrm{FE}$ of $48.9 \%$ (Fig. 3b). The trend of carboxylate production rates follows closely the diffusion rate of alcohols across the AEMs (Fig. 3b). For FAA-3-50, when switching from $\mathrm{IrO}_{\mathrm{x}}$ to $\mathrm{NiFeO}_{\mathrm{x}}$ as the anode, the carboxylate partial current density was increased substantially to $213.7 \mathrm{~mA} \mathrm{~cm}^{-2}$. In contrast, the mTPN1-TMA case showed less improvement and the FAAM-40 case showed little change (Fig. $3 \mathrm{c}$ ). Furthermore, the production ratio towards carboxylates when comparing $\mathrm{NiFeO}_{\mathrm{x}}$ and $\mathrm{IrO}_{\mathrm{x}}$ is a maximum of 3.7 times higher when using a highly diffusive membrane such as FAA3-50 (Fig. 3d). This is opposed to 2.8 times higher for moderately diffusive membrane such as mTPN1TMA and 1.4 times higher for FAAM-40. Importantly this led to an improvement in carboxylate purity from $75 \%$ when using FAAM-40 to $93 \%$ when using FAA-3-50. Therefore the use of diffusive membrane greatly improves both the ability to concentrate target products as well as leads to greater ability to purify them using the tandem strategy.

As shown in Fig. 3b, mTPN1-TMA exhibited the highest production rate towards carboxylates from the cathode alone, achieving a partial current density of $122.4 \mathrm{~mA} \mathrm{~cm}^{-2}$ with the $\mathrm{IrO}_{\mathrm{x}}$ anode. Therefore, other membrane properties (Table S2) could also influence the product selectivity. For mTPN1-TMA, the substantially high water uptake relative to FAA-3-50 may impact the water transport to the cathode, leading to increased acetate/carboxylate production rates. FAAM-40 showed the worst performance towards eCOR, which could be attributed to the accumulation of alcohol products at the interface interrupting the hydrophobicity and stability of gas-diffusion electrode. Evidently, development of 
advanced membrane materials tailored for $\mathrm{CO}_{2} / \mathrm{CO}$ electrolysis technologies may offer new opportunities to further boost electrolyzer performance. ${ }^{28}$

\section{Impact Of Product Concentration On Separation Cost}

The liquid product concentration strongly influences product separation cost; however, product concentration has often been neglected in $\mathrm{CO}_{2} / \mathrm{CO}$ electrolysis process design. Here, we conducted a techno-economic analysis to assess how the acetate concentration in the product stream influences the total process cost and energy usage. Previous simulations have evaluated electrochemical acetate/acetic acid production costs, but to the best of the author's knowledge, none have considered concentration effects, downstream acetate protonation, and electrolyte recovery. ${ }^{13,29,30}$ The process evaluated in this work included the electrochemical production of high concentration acetate, the protonation of acetate to acetic acid, the separation of the acetic acid from the electrolyte via extractive distillation, and the recovery of the electrolyte using electrolysis (Figure S20 and S21). The design and choices for these models are discussed in Supplementary Discussion 4 and 5. A wide range of produced acetate concentrations were studied to illuminate their impact on the total process energy usage. The results (Fig. 4a) show that the energy usage associated with distillation dominates the total energy usage of acetic acid production across the full range of concentrations studied. The impact of distillation on total process cost was further demonstrated with the aid of a cost-sensitivity analysis that revealed the total process cost is most responsive to changes in distillation costs (Fig. 4b). These distillation costs increase non-linearly with reductions in the produced acetate concentration from the $\mathrm{CO}$ electrolyzer. The analysis confirmed that the liquid product concentration of $5 \mathrm{M}$ or higher is needed to substantially minimize the product separation cost, while at higher concentrations, the return diminishes (Fig. 4a).

Experimentally, an increased initial $\mathrm{KOH}$ concentration was required to increase product concentration, purity, and carbon selectivity (Figure S7). Although the highest acetate concentration was observed using $7 \mathrm{M} \mathrm{KOH}$, nearly $100 \%$ acetate purity was obtained using $5 \mathrm{M} \mathrm{KOH}$ yielding $5.28 \mathrm{M}$ acetate. At $5 \mathrm{M} \mathrm{KOH}$, the highest acetate faradaic efficiency was achieved (Figure S7), indicating that the corresponding concentration of $\sim 5 \mathrm{M}$ acetate is likely to be the optimal product concentration under the reaction conditions in this study. Currently, $\mathrm{CO}$ electrolyzer components, specifically the cathode gas diffusion layers, anion exchange membranes, and anode catalysts, are not stable enough for long-term commercial operations (thousands of hours or more) in either extremely alkaline conditions (Figure S7) or under neutral to acidic $\mathrm{pH}$ (Figure S6 and S31) respectively. Therefore, more efforts are needed to tackle these material related challenges to achieve the long-term stability required for commercialization.

\section{Conclusion}

In this work, we presented a new "internally coupled purification" strategy in CO electrolysis to produce a high purity, concentrated acetate product stream. By incorporating a selective alcohol partial oxidation anode and an alcohol permeable anion exchange membrane in the $\mathrm{CO}$ electrolyzer, the acetate selectivity 
was dramatically increased via the rapid ethanol product crossover from the cathode as well as the ethanol partial oxidation at the anode. At the optimal conditions, an acetate product stream with a concentration of $7.6 \mathrm{M}$ and a purity of $>97 \%$ was obtained. Additionally, stable 120-hour operation was achieved with the state-of-the-art Orion Polymer AMX membrane. Both the anode material and membrane characteristics strongly impact the eCOR product selectivity. Based on the techno-economic analysis, a concentrated liquid product steam of at least $5 \mathrm{M}$ acetate is required to minimize separation cost. At lower acetate concentrations, the $\mathrm{CO}$ electrolysis process is unlikely to be commercially viable because of the high energy consumption for separation. This discovery may inspire new research in the rational design of advanced membrane materials and anode electrocatalysts tailored explicitly for $\mathrm{CO}_{2} / \mathrm{CO}$ electrolysis technologies and new strategies to target highly concentrated product streams especially for liquid products.

\section{Methods}

\section{Electrode Preparation Cathode Preparation}

Cathodes for carbon monoxide reduction were produced using commercially available copper nanoparticles (Cu 40-60 nm, Sigma-Aldrich). $100 \mathrm{mg}$ of copper nanoparticles were dispersed with $5 \mathrm{wt} \%$ (metal basis) carbon black (Vulcan XC 72, Fuel Cell Store) and 5 wt\% (metal basis) Nafion ionomer (D1021 Nafion Dispersion, Fuel Cell Store) in $20 \mathrm{~mL}$ of a 1:1 mixture of isopropyl alcohol (ACS Reagent) and deionized water. The mixture was sonicated for one hour to ensure complete dispersion, before being spray casted onto carbon paper at $120^{\circ} \mathrm{C}$ (Sigracet 39BB, lon Power). Once a loading of $0.5 \mathrm{mg} \mathrm{cm}^{-2}$ was measured, catalysts were allowed to dry over night at $70^{\circ} \mathrm{C}$ to ensure complete evaporation of solvents (Figure S20).

For reinforced gas diffusion layers a mixture of $100 \mathrm{mg}$ carbon black and $20 \mathrm{mg}$ Teflon dispersion was dispersed in a 1:1 mixture of isopropyl alcohol and deionized water. The mixture was allowed to sonicate for 30 minutes to allow complete dispersion. The mixture was then sprayed onto carbon paper at $120^{\circ} \mathrm{C}$ until a total loading of $10 \mathrm{wt} \%$ of the carbon paper was achieved. The reinforced gas diffusion layer was then placed in a furnace at $350^{\circ} \mathrm{C}$ for 15 minutes to allow the Teflon to adhere to the carbon paper support. The layer was then allowed to cool. Cu nanoparticles were sprayed in the same manner as will unsupported carbon paper gas diffusion layers.

Cathodes for anode oxidation experiments were produced using a similar procedure to carbon monoxide electroreduction. Pt nanoparticles (47\% Pt/C, TKK) was dispersed with a $5 \mathrm{wt} \%$ Nafion ionomer in a 1:1 mixture of isopropyl alcohol and deionized water. The ink was then spray casted onto carbon paper at $120^{\circ} \mathrm{C}$ and allowed to dry overnight to ensure complete evaporation of solvents.

\section{Anode Preparation}


Nickel foam based anodes were prepared based on a previous report. ${ }^{27}$ Porous nickel foam $(>99.99 \%$, MTI Corporation) was washed using ethanol, acetone, and deionized water before being sonicated in $5 \mathrm{M}$ $\mathrm{HCl}$ (ACS Reagent) for 30 minutes to remove any surface nickel oxides. The electrodes were then once again rinsed in ethanol and deionized water and dried prior to electrodeposition of metals. For all depositions, a platinum wire was used as the counter electrode and an $\mathrm{Ag} / \mathrm{AgCl}$ (Pine Research) reference electrode was used as the reference electrode. $\mathrm{For}_{\mathrm{NiFeO}}$ anodes, the cleaned nickel foam was submerged in a solution containing $3 \mathrm{mM} \mathrm{Ni}\left(\mathrm{NO}_{3}\right)_{2}: 6 \mathrm{H}_{2} \mathrm{O}$ (Sigma Aldrich) and $3 \mathrm{mM} \mathrm{Fe}\left(\mathrm{NO}_{3}\right)_{3}: 9 \mathrm{H}_{2} \mathrm{O}$ (Sigma Aldrich). A potential of $-1.0 \mathrm{~V}$ vs. Ag/AgCl was applied to the nickel foam and held for 5 minutes using a potentiostat (PGSTAT128N, Metrohm Autolab). Once deposition was completed, electrode was once again rinsed in ethanol, deionized water, and then dried overnight. For the $\mathrm{CoO}_{\mathrm{x}} / \mathrm{Ni}$ anodes, the same procedure was followed using a solution containing $6 \mathrm{mM} \mathrm{Co}\left(\mathrm{NO}_{3}\right)_{2}: 6 \mathrm{H}_{2} \mathrm{O}(98 \%$, Sigma Aldrich). Foams were compressed prior to use. Unaltered nickel foam was used as the anode for the bare Ni foam experiments.

Iridium oxide anodes were prepared based on a previous report. ${ }^{31}$ Titanium felt (Fuel Cell Store) was degreased using acetone and deionized water and was etched in boiling $0.5 \mathrm{M}$ oxalic acid ( $98 \%$, Sigma Aldrich). Titanium felts were then dip coated using a solution of isopropyl alcohol (ACS reagent), $10 \mathrm{vol} \%$ $\mathrm{HCl}$, and dissolved $\mathrm{IrCl}_{3}: \mathrm{xH}_{2} \mathrm{O}\left(99.8 \%\right.$, Alfa Aesar). The dip coated titanium was dried at $100{ }^{\circ} \mathrm{C}$ for 10 minutes followed by calcination at $500^{\circ} \mathrm{C}$ for 10 minutes in air. Loading was tracked via mass, and dip coating was repeated until a loading of $4 \mathrm{mg} \mathrm{cm}^{-2}$ was reached.

\section{H-Cell Experiments}

For cyclic voltammetry (CV) experiments, prepared electrodes were connected to a silver wire $(0.5 \mathrm{~mm}$ dia Ag wire, $1 \frac{1}{2}$ hard, $99.9 \%$, Alfa Aesar) using silver paint ( $\left(\mathrm{rO}_{\mathrm{x}}\right)$ or via soldering ( $\mathrm{Ni}$ based foams) and allowed to dry overnight. H-cell experiments were completed in a two-compartment custom glass cell (Adams \& Chittenden). The two halves were separated using an FAA-3-50 (Fumatech) membrane. The cells were filled to a fixed height using solutions of either $1 \mathrm{M} \mathrm{KOH}$ (Pellets, $85 \%$, Alfa Aesar) or $1 \mathrm{M} \mathrm{KOH}+$ ethanol (200 proof, Decon Labs). The ethanol concentration was varied based on the experiment. An active submerged area of $0.7 \mathrm{~cm}^{2}$ was measured for all experiments. A Hg/HgO reference electrode (Koslow) was used as the reference electrode. Potentials were $85 \%$ iR corrected based off i-interrupt resistance measurements. Argon gas was bubbled through the electrolyte for 30 minutes prior to experiment and flowed through the headspace throughout the tests. Linear sweep voltammetry (LSV) data was collected by sweeping the electrode from 0.7 to $1.8 \mathrm{~V}$ vs. RHE at a scan rate of $25 \mathrm{mV} \mathrm{s}^{-1}$. LSVs were repeated for both $1 \mathrm{M} \mathrm{KOH}$ and $1 \mathrm{M} \mathrm{KOH}+1 \mathrm{M}$ ethanol (Figure S21 and S22).

\section{Membrane Electrode Assembly Experiments}

\section{Membrane Electrode Assembly Preparation}


Membrane electrode assembly (MEA) experiments were carried out using in house manufactured serpentine flow channels. End plates were manufactured using 304 stainless steels and were then coated in a 2-micron layer of gold to ensure passivation. Teflon gaskets ( 0.01 ", McMaster-Carr) were laser cut to ensure fit and were used to seal the cathode and anode compartments. FAA-3-50 was used as the conductive membrane and was activated in $1 \mathrm{M} \mathrm{KOH}$ for 24 hours prior to use. For experiments using FAAM-40, FAAM-40 (Fumatech) was activated in $9 \mathrm{M} \mathrm{KOH}$ overnight and rinsed thoroughly in $2 \mathrm{M} \mathrm{KOH}$ prior to use. For the long-term stability experiments, either mTPN1-TMA membrane (synthesized) or AMX membrane (Orion Polymer) was used. mTPN1-TMA and AMX membranes were activated in $1 \mathrm{M} \mathrm{KOH}$ for 24 hours prior to use. Electrodes were placed on either side of the conductive membrane and the cell was compressed using a torque wrench.

\section{Carbon Monoxide Reduction Experiments}

All carbon monoxide electroreduction experiments were performed using a Cu nanoparticle cathode. Carbon monoxide gas was fed to the cathode endplate using a mass flow controller (GF040, Brooks Instruments). The pressure was held at 15.5 psia using a digital backpressure controller (Cole-Parmer). Anolyte was fed to the system using a peristaltic pump (Cole-Parmer) at a constant rate. Potential was applied and measured using a potentiostat (PGSTAT128N, Metrohm Autolab) along with a 10 A booster (BOOSTER10A, Autolab). Gas products were analyzed using an inline gas chromatogram (SRI Instruments) equipped with a HayeSep D column. Argon gas (99.999\%) was used as the carrier for the gas chromatogram. For single pass experiments, $2 \mathrm{M} \mathrm{KOH}$ was used as the anolyte. The cell was allowed to run at each applied current for 20 minutes, after which the anolyte was collected for 5 minutes. The anolyte was then diluted significantly using deionized water before being analyzed via water suppression quantitative NMR (Bruker AVIII $600 \mathrm{MHz}$ ). Prepared $25 \mathrm{ppm}$ dimethyl sulfoxide (DMSO) standard in $\mathrm{D}_{2} \mathrm{O}$ was used as an internal standard for quantification. Some products were also collected in a cold trap comprised of an airtight trap downstream of the CO outlet. The trap was placed in an ice bath prior to the backpressure controller to avoid vaporization of volatile products. Gas products during single pass experiments were collected using the inline gas chromatogram after 15 and 30 minutes. FAAM-40 experiments were performed in the same way as FAA-3-50 experiments; however, most products were detected in the catholyte trap.

For recirculation experiments, the anolyte was recirculated through the anode compartment and back into the reservoir. Recirculation was completed using 1, 2, 3, 5, 7, or $9 \mathrm{M} \mathrm{KOH}$ depending on the experiment. For maximum concentration experiments, AMX membrane, reinforced cathodes, and $\mathrm{NiFeO}_{\mathrm{x}}$ anode were utilized. A small amount of $\mathrm{KOH}$ was allowed to recirculate until the cell potential was above $2.8 \mathrm{~V}$, at which point the potentiostat would automatically end the experiment. After recirculation, a sample from the anolyte was diluted and analyzed using quantitative NMR. To actively track the $\mathrm{pH}$ of the system, a digital pH meter (pH400s, Apera Instruments) was immersed in the electrolyte and the $\mathrm{pH}$ was recorded every minute. The FE calculated was based on the total molar production of products found in the anolyte over the duration of the experiment and is an average. For semi-batch recirculation experiments, a set volume of anolyte was allowed to circulate through the electrolyzer, between 50 and $100 \mathrm{~mL}$ based on 
the experiment. After approximately 24 hours, fresh anolyte was fed into the reactor and allowed to recirculate. Current density was fixed at $200 \mathrm{~mA} \mathrm{~cm}^{-2}$ and $\mathrm{CO}$ was flowed at a set rate of $10 \mathrm{sccm}$. Collected anolytes were diluted and analyzed via quantitative ${ }^{1} \mathrm{H}-\mathrm{NMR}$. Gaseous products were collected every hour or every 4 hours via automated injection.

To measure the oxygen production from the anode, a gas-liquid separator was placed in the anode outlet. Argon gas $\left(99.9999 \%\right.$, Keene) was bubbled through the separator at a rate of $100 \mathrm{~mL} \mathrm{~min}^{-1}$ and the oxygen gas was measured using an in-line GC.

\section{Alcohol Oxidation Experiments}

Alcohol oxidation experiments were performed in the same MEA configuration as described for carbon monoxide reduction. A Pt/C cathode was used as the counter electrode, and an external $\mathrm{Hg} / \mathrm{HgO}$ reference electrode utilizing a Luggin Capillary was used for measuring the applied potential to the anode. A mixture containing 0.5 M ethanol, 0.5 M n-propanol (ACS Reagent), and $2 \mathrm{M} \mathrm{KOH}$ was continuously supplied to the anode and collected following oxidation. Products were then analyzed using quantitative NMR as described for eCOR. Argon gas was fed to the cathode to purge the headspace. For experiments involving solely $2 \mathrm{M} \mathrm{KOH}$ or $2 \mathrm{M} \mathrm{KOH}+1 \mathrm{M}$ ethanol, a similar procedure was followed, with the sole difference being the supporting electrolyte used. Potentials were $85 \%$ iR-corrected using resistance values found via i-interrupt.

\section{Material Characterization}

X-ray photoelectron spectroscopy (XPS) was completed on samples before and after testing. All presamples were exposed to air due to the storage of catalysts in ambient conditions. For post-reaction, all samples were washed thoroughly with IPA and water to remove any residuals from the experiments. $\mathrm{Cu}$ samples were stored under argon, to prevent the formation of surface oxides from contact with air. XPS equipment (K-Alpha X-ray photoelectron spectrometer system, Thermo Fisher Scientific) was used to obtain high-resolution XPS measurements at pass energy of $20 \mathrm{eV}$ with a step size of $0.1 \mathrm{cV}$. Flood gun was turned on. $\mathrm{Cu} 2 \mathrm{P}$, Ni 2P, Fe 2P, Fe 3P, Co 2P, Ir 4f, and Ti 2p (based on anode) were scanned 10 times depending on the sample being processed. All peaks were fitted using Thermo Advantage software. Scanning electron microscopy images were performed prior to experiment using an Auriga 60 Crossbeam $(3 \mathrm{kV})$. An energy dispersive X-ray analysis system was used for elemental mapping.

Product crossover rates were performed via a static-diffusion experiment using an $\mathrm{H}$-cell divided by the membrane of choice. In one compartment a solution containing $2 \mathrm{M} \mathrm{KOH}$ was added. Into the other chamber a solution containing $2 \mathrm{M} \mathrm{KOH}+0.5 \mathrm{M}$ ethanol $+0.5 \mathrm{M} \mathrm{n}$-propanol or $2 \mathrm{M} \mathrm{KOH}+0.5 \mathrm{M}$ ethanol + $0.5 \mathrm{M} \mathrm{n}$-propanol $+0.5 \mathrm{M}$ acetate was added. Samples were taken from the compartment holding $2 \mathrm{M}$ $\mathrm{KOH}$ every 30 minutes (starting at time $=0$ minutes) and analyzed via quantitative ${ }^{1} \mathrm{H}-\mathrm{NMR}$. No mixing was induced to ensure crossover was solely determined by concentration gradients and to remove convective effects.

\section{Techno-economic Analysis}


The techno-economic model for acetate production used in this work was based on our previously published model. ${ }^{19}$ Minor adjustments to this model were made to capture the true acetic acid production cost more accurately (Table S3). Performance parameters including current density, cell voltage, and faradaic efficiency were based off the experimental performance observed in this work. Stack cost was determined using the same method as the previous model but adjusted to reflect the true Ir anode loading used in this study $\left(4 \mathrm{mg} \mathrm{cm}^{-2}\right)$. All adjustments to the previous model can be found in Supplementary Table 3. The production cost was determined by evaluating a selling cost that resulted in a net present value of zero at the end of process life assuming a 20-year plant lifespan. A production scale of 50,000 $\mathrm{kg} \mathrm{day}^{-1}$ was chosen to be consistent with the scale of previous work and to be reflective of a commercialized process. ${ }^{19} 100 \%$ acetate purity was assumed at the electrolyzer outlet, which is acceptable as $>97 \%$ acetate purity was demonstrated experimentally. Electrolyte recovery and formate protonation costs were modeled using hydrochloric acid cycling based on industrial scale $\mathrm{NaCl}$ electrolyzers widely used for hydrochloric acid production in the chloroalkali industry. A detailed explanation of the formate protonation and electrolyte recovery costs can be found in Supplementary Discussion 4. Distillation costs and energy usage were evaluated using ASPEN Plus software with the Economic Analyzer and Energy Analyzer plug-ins. Each acetate concentration indicated in Figure (4a) was modeled independently in ASPEN using an extractive distillation process to produce $89 \%-94 \%$ acetic acid. Additional details on the ASPEN separation model can be found in Supplementary Note $x$. The market price of the carbon monoxide feed sourced from syngas ( $0.06 \mathrm{USD} \mathrm{kg}^{-1}$ ) was determined as previously reported. ${ }^{32}$ The cost analysis provided in Figure (4b) was based on a 20-year plant lifespan, normalizing both capital and operating costs.

\section{Declarations}

\section{Acknowledgements}

This material is based upon work supported by the U.S. Department of Energy under Award Number DEFE0031910.

\section{Author contributions}

S.O. conducted the experiments, performed the data analysis, and wrote the first draft of the manuscript. B.C. conducted the techno-economic analysis. B.S. and D.T. produced and conducted the analysis of the Orion membrane. B.H.K. performed the XPS measurements and analysis the XPS data. H.S. conducted the scanning electron microscopy measurements. C.B. supervised the synthesis of the Orion membranes. 
F.J. revised the manuscript and supervised the whole project. All authors commented on the final version of the manuscript.

\section{Competing interests}

The authors declare no competing interests.

\section{References}

1. Overa, S., Feric, T. G., Park, A. H. A. \& Jiao, F. Tandem and Hybrid Processes for Carbon Dioxide Utilization. Joule 5, 8-13 (2021).

2. Bushuyev, O. S. et al. What Should We Make with $\mathrm{CO}_{2}$ and How Can We Make It? Joule 2, 825-832 (2018).

3. Nitopi, S. et al. Progress and Perspectives of Electrochemical $\mathrm{CO}_{2}$ Reduction on Copper in Aqueous Electrolyte. Chem. Rev. 119, 7610-7672 (2019).

4. Jeng, E. \& Jiao, F. Investigation of $\mathrm{CO}_{2}$ single-pass conversion in a flow electrolyzer. React. Chem. Eng. 5, 1768-1775 (2020).

5. Rabinowitz, J. A. \& Kanan, M. W. The future of low-temperature carbon dioxide electrolysis depends on solving one basic problem. Nat. Commun. 11, 5231 (2020).

6. Cofell, E. R., Nwabara, U. O., Bhargava, S. S., Henckel, D. E. \& Kenis, P. J. A. Investigation of ElectrolyteDependent Carbonate Formation on Gas Diffusion Electrodes for $\mathrm{CO}_{2}$ Electrolysis. ACS Appl. Mater. Interfaces 13, 15132-15142 (2021).

7. Li, Y. C. et al. $\mathrm{CO}_{2}$ Electroreduction from Carbonate Electrolyte. ACS Energy Lett. 4, 1427-1431 (2019).

8. Yan, Z., Hitt, J. L., Zeng, Z., Hickner, M. A. \& Mallouk, T. E. Improving the efficiency of $\mathrm{CO}_{2}$ electrolysis by using a bipolar membrane with a weak-acid cation exchange layer. Nat. Chem. 13, 33-40 (2021).

9. Huang, J. E. et al. $\mathrm{CO}_{2}$ electrolysis to multicarbon products in strong acid. Science 372, 1074-1078 (2021).

10. Cuellar, N. S. R., Scherer, C. \& Ka, B. Two-step electrochemical reduction of $\mathrm{CO}_{2}$ towards multi-carbon products at high current densities. J. $\mathrm{CO}_{2}$ Util. 36, 263-275 (2019).

11. Ozden, A. et al. Cascade $\mathrm{CO}_{2}$ electroreduction enables efficient carbonate-free production of ethylene. Joule 5, 706-719 (2021). 
12. Ripatti, D. S., Veltman, T. R. \& Kanan, M. W. Carbon Monoxide Gas Diffusion Electrolysis that Produces Concentrated $C_{2}$ Products with High Single-Pass Conversion. Joule 3, 240-256 (2019).

13. Jouny, M., Hutchings, G. S. \& Jiao, F. Carbon monoxide electroreduction as an emerging platform for carbon utilization. Nat. Catal. 2, 1062-1070 (2019).

14. Luc, W. et al. Two-dimensional copper nanosheets for electrochemical reduction of carbon monoxide to acetate. Nat. Catal. 2, 423-430 (2019).

15. Li, C. W., Ciston, J. \& Kanan, M. W. Electroreduction of carbon monoxide to liquid fuel on oxidederived nanocrystalline copper. Nature 508, 504-507 (2014).

16. Jouny, M., Luc, W. \& Jiao, F. High-rate electroreduction of carbon monoxide to multi-carbon products. Nat. Catal. 1, 748-755 (2018).

17. Zhu, P. et al. Direct and continuous generation of pure acetic acid solutions via electrocatalytic carbon monoxide reduction. PNAS 118, e2010868118 (2021).

18. Monteiro, M. C. O. et al. Absence of $\mathrm{CO}_{2}$ electroreduction on copper, gold and silver electrodes without metal cations in solution. Nat. Catal. 4, 654-662 (2021).

19. Shin, H., Kentaro, H. \& Jiao, F. Techno-economic assessment of low-temperature carbon dioxide electrolysis. Nat. Sustain. 4, 911-919 (2021).

20. Zhu, P. \& Wang, H. High-purity and high-concentration liquid fuels through $\mathrm{CO}_{2}$ electroreduction. Nat. Catal. 4, 943-951 (2021).

21. Miller, M. \& Bazylak, A. A review of polymer electrolyte membrane fuel cell stack testing. J. Power Sources 196, 601-613 (2011).

22. Marx, N., Boulon, L., Gustin, F., Hissel, D. \& Agbossou, K. A review of multi-stack and modular fuel cell systems: Interests, application areas and on-going research activities. Int. J. Hydrogen Energy 39, 12101-12111 (2014).

23. Selamet, Ö. F., Becerikli, F., Mat, M. D. \& Kaplan, Y. Development and testing of a highly efficient proton exchange membrane (PEM) electrolyzer stack. Int. J. Hydrogen Energy 36, 11480-11487 (2011).

24. Noh, S., Jeon, J. Y., Adhikari, S., Kim, Y. S. \& Bae, C. Molecular Engineering of Hydroxide Ion Conducting Anion Exchange Polymers for Electrochemical Energy Conversion Technology. Acc. Chem. Res. 52, 2745-2755 (2019).

25. Dinh, C. T. et al. $\mathrm{CO}_{2}$ electroreduction to ethylene via hydroxide-mediated copper catalysis at an abrupt interface. Science 360, 783-787 (2018).

26. Yuan, N., Jiang, Q., Li, J. \& Tang, J. A review on non-noble metal based electrocatalysis for the oxygen evolution reaction. Arab. J. Chem. 13, 4294-4309 (2020).

27. Lu, X. \& Zhao, C. Electrodeposition of hierarchically structured three-dimensional nickel-iron electrodes for efficient oxygen evolution at high current densities. Nat. Commun. 6, 6616 (2015).

28. Galli, F. et al. Simulation of the water-acetic acid separation via distillation using different entrainers: An economic comparison. Chem. Eng. Trans. 57, 1159-1164 (2017). 
29. Spurgeon, J. M. \& Kumar, B. A comparative technoeconomic analysis of pathways for commercial electrochemical $\mathrm{CO}_{2}$ reduction to liquid products. Energy Environ. Sci. 11, 1536-1551 (2018).

30. Ramdin, M. et al. Electroreduction of $\mathrm{CO}_{2} / \mathrm{CO}$ to $\mathrm{C}_{2}$ Products: Process Modeling, Downstream Separation, System Integration, and Economic Analysis. Ind. Eng. Chem. Res. 60, 17862-17880 (2021).

31. Luc, W., Rosen, J. \& Jiao, F. An Ir-based anode for a practical $\mathrm{CO}_{2}$ electrolyzer. Catal. Today $\mathbf{2 8 8}$, 7984 (2017).

32. Jouny, M., Luc, W. \& Jiao, F. General Techno-Economic Analysis of $\mathrm{CO}_{2}$ Electrolysis Systems. Ind. Eng. Chem. Res. 57, 2165-2177 (2018).

\section{Figures}

\section{Figure 1}

Production of concentrated acetate streams via eCOR. (a) Schematic of the $\mathrm{CO}$ electrolyzer design in an MEA configuration using a permeable AEM to produce a concentrated acetate stream in the anolyte chamber. (Blue) Initial reduction of $\mathrm{CO}$ on the Cu catalyst surface (cathode) to a variety of products. (Purple) Diffusion of liquid products through the AEM to the anolyte. (Green) Secondary reaction, partial oxidation of alcohol (mainly ethanol) from $\mathrm{CO}$ reduction to carboxylates (mainly acetate), resulting in a concentrated and purified product stream. (b) Performance of eCOR system, FE (left) of acetate, hydrogen, and ethylene and total cell potential measured (right). The cell was operated at a fixed current density of $200 \mathrm{~mA} \mathrm{~cm}^{-2}$ using $3 \mathrm{M} \mathrm{KOH}$ electrolyte, reinforced $\mathrm{Cu}$ nanoparticle cathode, $\mathrm{NiFeO}_{\mathrm{x}} / \mathrm{Ni}$ foam anode, and Orion Polymer AMX anion exchange membrane. $\mathrm{CO}$ was fed at a rate of $10 \mathrm{sccm}$. (c) Anolyte concentrations for all liquid products (left) and acetate purity (right). (d) Maximum achievable concentrations (left) and purity (right) for acetate in internal tandem design using varying starting concentrations of $\mathrm{KOH}$. 
a

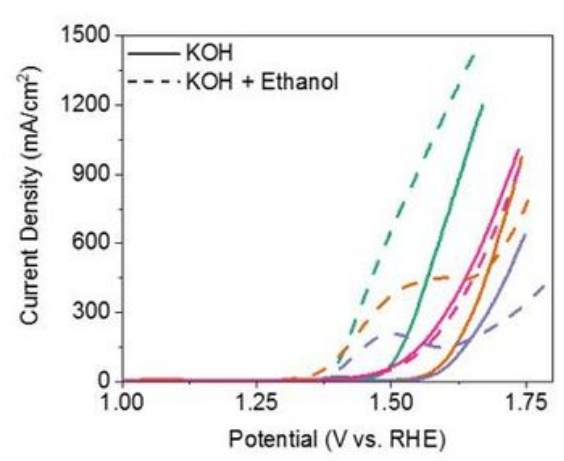

b

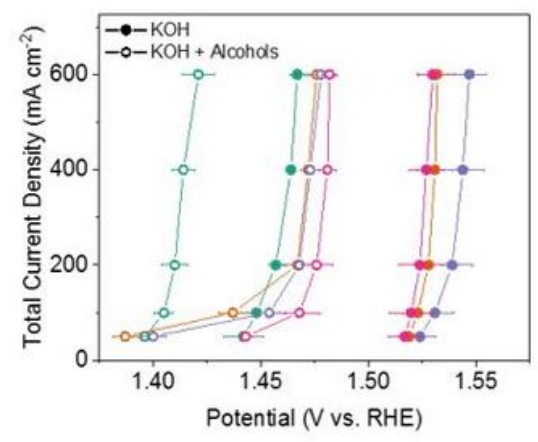

C

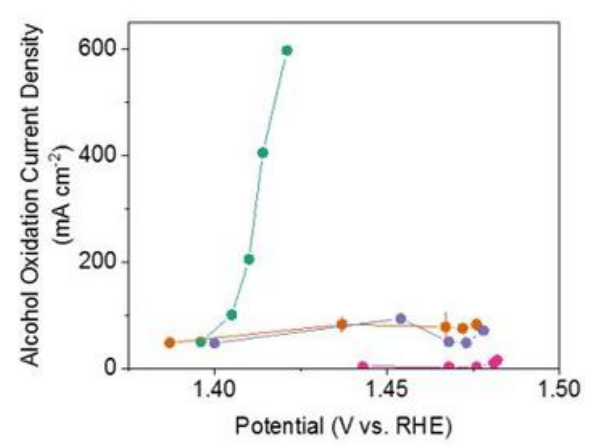

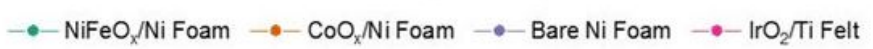

d

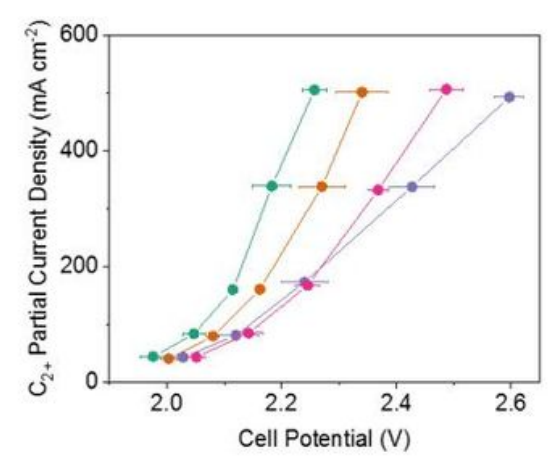

e

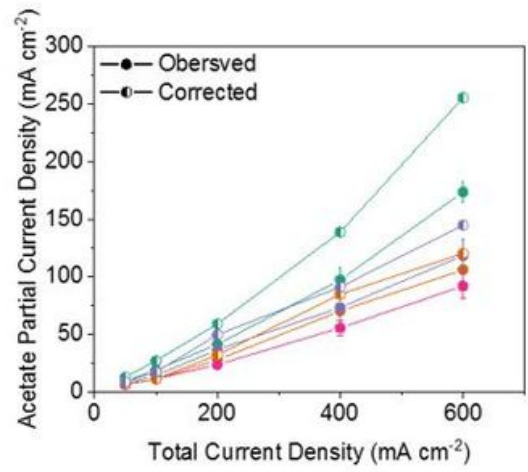

f

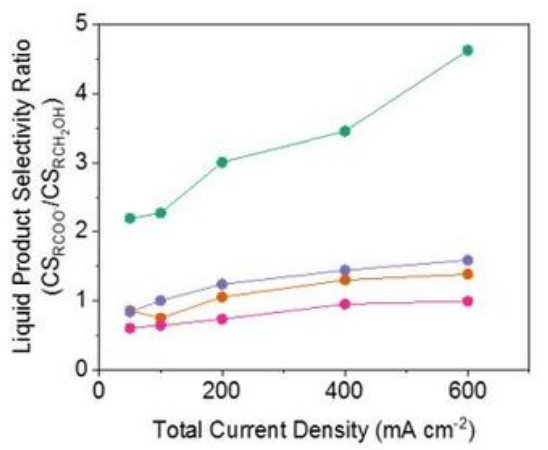

Figure 2

Anodic impact on selectivity via the partial oxidation of alcohols. (a) Linear sweep voltammograms for $\mathrm{NiFeO}_{\mathrm{x}}$ electrodeposited on $\mathrm{Ni}$ foam (green), $\mathrm{CoO}_{\mathrm{x}}$ electrodeposited on Ni foam (orange), bare $\mathrm{Ni}$ foam (purple), and $\mathrm{IrO}_{\mathrm{x}}$ calcinated onto Ti felt (magenta). Anodes were swept from 0.75 to $1.75 \mathrm{~V}$ at a scan rate of $25 \mathrm{mV} \mathrm{s}^{-1}$. KOH sweep was performed in $1 \mathrm{M} \mathrm{KOH}$ (solid) and $\mathrm{KOH}+$ ethanol (dashed) was performed in $1 \mathrm{M} \mathrm{KOH}$ and $1 \mathrm{M}$ ethanol solution. (b) Measured oxidation current density of anodes in $1 \mathrm{M} \mathrm{KOH}$ $(\mathrm{KOH}$, closed circle) and $1 \mathrm{M} \mathrm{KOH}, 0.5 \mathrm{M}$ ethanol, and 0.5 M n-propanol ( $\mathrm{KOH}+$ Alcohols, open circle). Experiments used an MEA style electrolyzer. (c) Partial current density measured for partial oxidation of alcohols to carboxylates. (d) Multi-carbon $\left(\mathrm{C}_{2+}\right)$ partial current density for eCOR performed at $20 \mathrm{sccm} \mathrm{CO}$ feed and $2 \mathrm{M} \mathrm{KOH}$ using an FAA-3-50 membrane. (e) Acetate partial current density (solid) and corrected acetate partial current density (half-solid) at applied current densities for all anodes. (f) Carbon selectivity ratio for observed carboxylates ( $\left.\mathrm{CS}_{\mathrm{RCOO}}\right)$ and observed alcohols $\left(\mathrm{CS}_{\mathrm{RCH} 2 \mathrm{OH}}\right)$ at applied total current densities. All half-cell potentials were measured using a $\mathrm{Hg} / \mathrm{HgO}$ reference electrode and manually iR corrected at $85 \%$ resistance measured via i-interrupt. Full cell potentials were not iR corrected. Error bars represent the standard deviation of three independent experiments. 
a

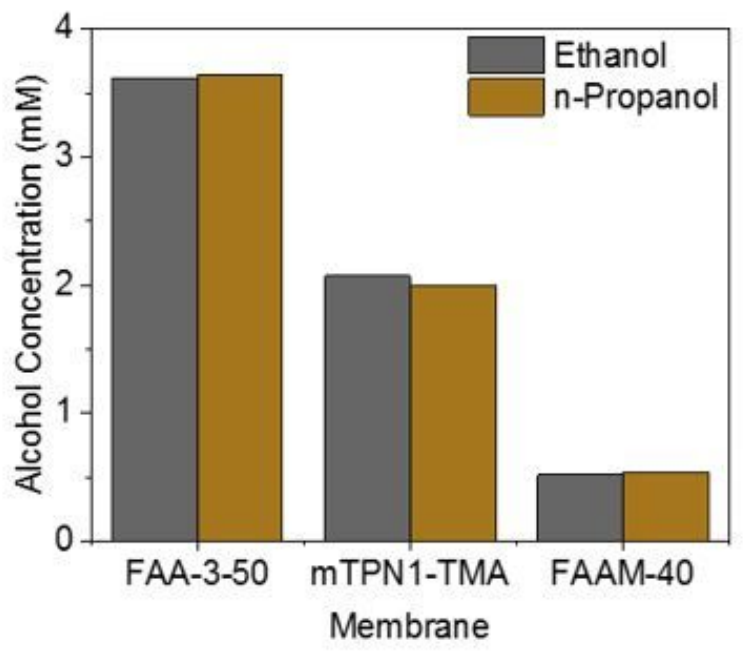

C

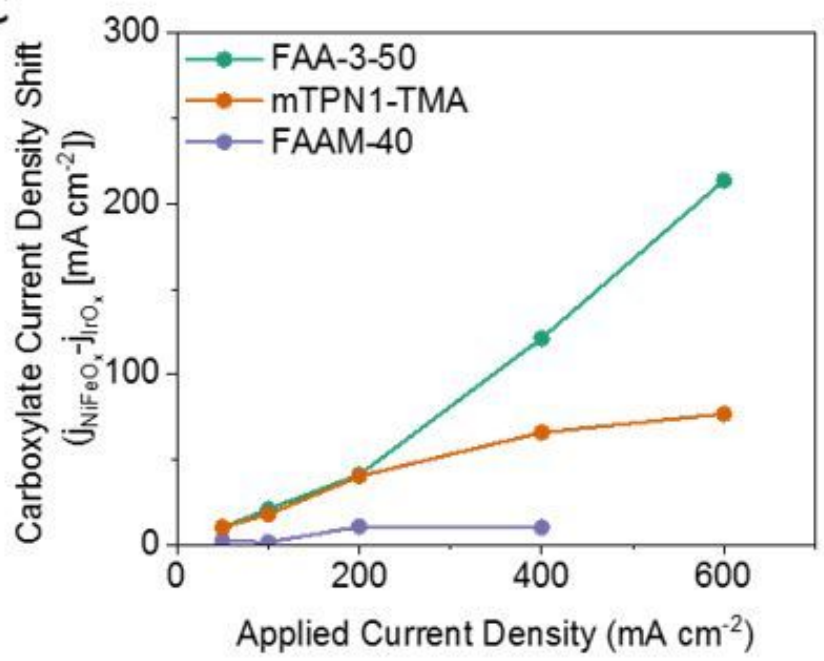

b

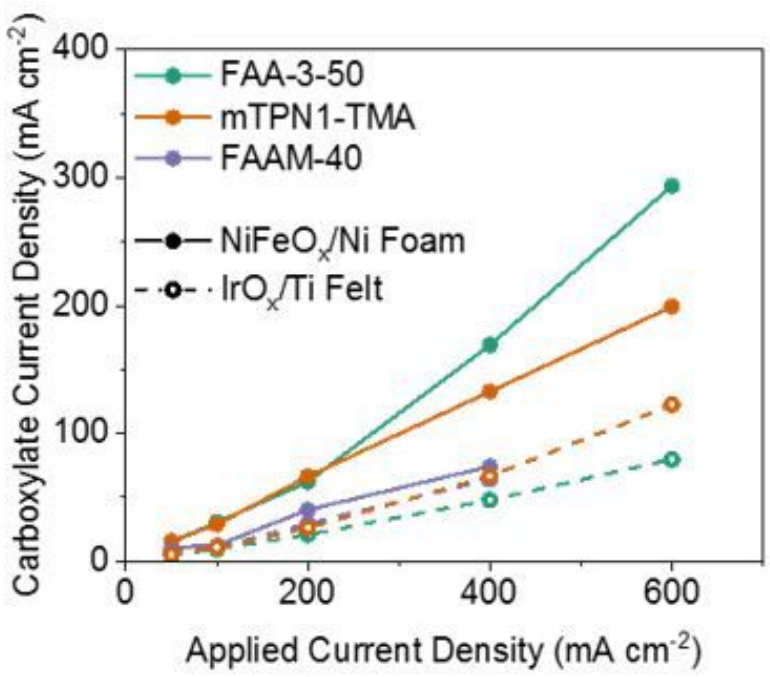

d

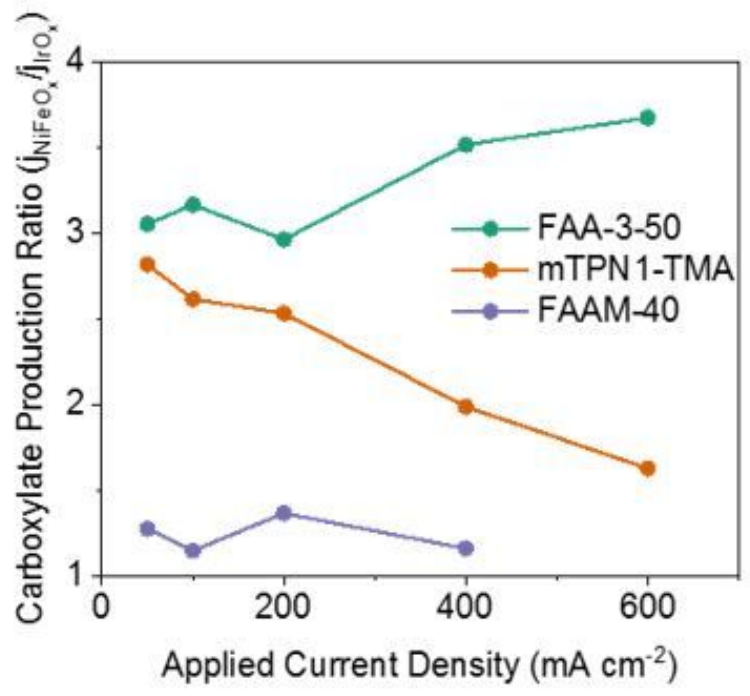

Figure 3

Membrane crossover rate influence on eCOR selectivity. (a) The measured concentration of ethanol and n-propanol after 2 hours from a static diffusion experiment. $10 \mathrm{~mL}$ of a solution containing $2 \mathrm{M} \mathrm{KOH}, 0.5$ $\mathrm{M}$ ethanol, and $0.5 \mathrm{M}$ n-propanol was divided from a solution containing $10 \mathrm{~mL}$ of $2 \mathrm{M} \mathrm{KOH}$ by the listed membrane. The concentration of alcohols was measured every 30 minutes. (b) Corrected partial current density towards carboxylates (acetate and propionate) during eCOR. All experiments were performed using Cu nanoparticle cathode and $2 \mathrm{M} \mathrm{KOH}$ electrolyte at $20 \mathrm{sccm} \mathrm{CO}$ feed rate. (c) Shift in carboxylate current densities by switching anodes from $\mathrm{IrO}_{\mathrm{x}}$ to $\mathrm{NiFeO}_{\mathrm{x}}$. (d) Production ratio of carboxylates between $\mathrm{NiFeO}_{\mathrm{x}}$ and $\mathrm{IrO}_{\mathrm{x}}$ anodes. 

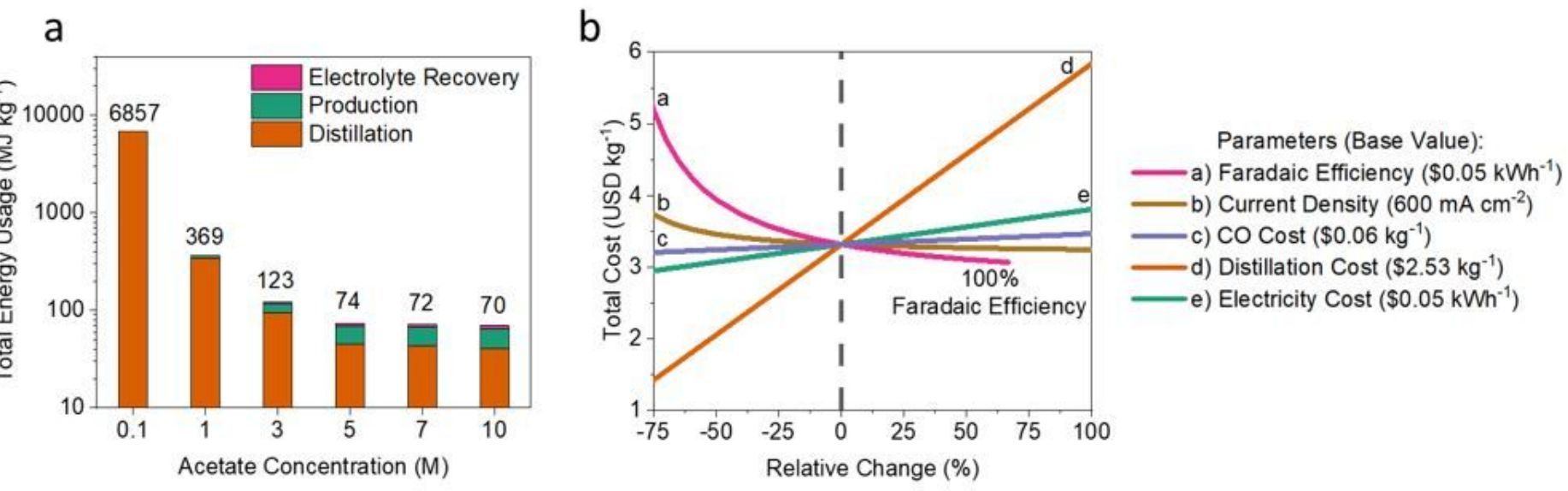

\section{Figure 4}

Techno-economic assessment of recirculative acetate production. (a) Effect of concentration on total energy usage including contributions from electrolyte recovery, production, and distillation. (b) Costsensitivity analysis of relevant process parameters for $5 \mathrm{M}$ acetate production. Values listed represent the base prices of the values shifted via the $x$-axis and are represented in the figure as the vertical grey dashed line.

\section{Supplementary Files}

This is a list of supplementary files associated with this preprint. Click to download.

- COReductionandAnodeSupportingInformationFinal.docx 